\title{
Modelo de gestão do curso técnico em apicultura na Educação a Distância da Universidade Federal do Piauí
}

\section{Model management of the technical course in beekeeping in Education Distance from the Piauí Federal University}

Recebido: 01/08/2019 | Revisado: 22/11/2019 | Aceito: 04/01/2021 | Publicado: $17 / 05 / 2021$

\section{Soraya Oka Lobo}

ORCID: https://orcid.org/0000-0002-69172818

Universidade Tecnológica Federal do Paraná

E-mail: solloka@yahoo.com.br

Domingos Leite Lima Filho

ORCID: https://orcid.org/0000-0003-38026794

Universidade Tecnológica Federal do

Paraná

E-mail: dllfilho@gmail.com

\section{Laurielson Chaves Alencar}

Colégio Técnico de Floriano vinculado a

Universidade Federal do Piauí

E-mail: laurielson@yahoo.com.br

Como citar: LOBO, S.O.; LIMA FILHO, D. L.; ALENCAR, L.C. Modelo de gestão do curso técnico em apicultura na Educação a Distância da Universidade Federal do Piauí. Revista Brasileira da Educação Profissional e Tecnológica, [S.I.], v. 1, n. 20, p. e8853, maio. 2021. ISSN 24471801.

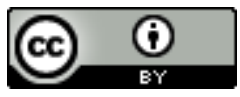

This work is licensed under a Creative Commons Attribution 4.0 Unported License.

\begin{abstract}
Resumo
No artigo analisa-se o modelo de gestão do Curso Técnico de Educação Profissional de nível médio em Apicultura, na modalidade Educação a Distância, da Universidade Federal do Piauí (UFPI), pertencente ao Programa da Rede eTec Brasil. Adotou-se a pesquisa de abordagem qualitativa, fundamentada em Stake (2011), utilizando-se a questão gerativa narrativa apoiada por Flick (2009) e Jovchelovich e Bauer (2010), além da análise bibliográfica e entrevistas realizadas no Colégio Técnico de Floriano com cinco colaboradores do curso pesquisado. Utilizou-se a técnica de análise de conteúdo, fundamentada por Bardin (2016). Constatou-se que a implantação de modelo de gestão colaborativo permitiu manter a qualidade do ensino técnico e profissional, adotando a figura do professor-pesquisador aliado ao trabalho do professor tutor-presencial, como processo interativo com estudantes-produtores rurais e um despertar para formação continuada na área.
\end{abstract}

Palavras-Chave: Educação a Distância; Modelo de Gestão; Curso Técnico em Apicultura.

\begin{abstract}
The article analyzes the management model of the Technical Course of Professional Education in Apiculture, in the Distance Education modality, at the Federal University of Piauí (UFPI), belonging to the eTec Brazil Network Program. It was adopted the research of qualitative approach, based on Stake (2011), using the generative narrative question supported by Flick (2009) and Jovchelovich and Bauer (2010), besides the bibliographical analysis and interviews conducted at Floriano Technical College with five collaborators of the researched course. The content analysis technique was used, based on Bardin (2016). It was found that the implementation of a collaborative management model allowed to maintain the quality of technical and vocational education, adopting the figure of the teacher-researcher allied to the work of the tutor-classroom teacher, as an interactive process with rural students-producers and an awakening for training continued in the area.
\end{abstract}

Keywords: Distance education; Management model; Technical Course in Beekeeping. 


\section{NOTAS INICIAIS}

O modelo de gestão educacional do Curso Técnico de Educação Profissional de nível médio em Apicultura, na modalidade Educação a Distância, da Universidade Federal do Piauí (UFPI), envolveu elementos de interação, (co)construção, cooperação no processo colaborativo, entre a figura do professor pesquisador, professor-tutor a distância e professor-tutor presencial, compartilhando métodos, procedimentos e metodologias, saberes experienciais e saberes técnicos e científicos, preocupando-se com o contexto da realidade em que os estudantes-produtores rurais vivem e atuam.

Esse trabalho, o qual está interconectado com a pesquisa mais abrangente do Doutorado Interinstitucional do Programa de Pós-Graduação em Tecnologia e Sociedade, da Universidade Tecnológica Federal do Paraná e da UFPI (DINTER PPGTE/UTFPR-UFPI) intitulada de "Correlações entre o trabalho dos técnicos em apicultura e as comunidades rurais pesquisadas da microrregião de São Raimundo Nonato: (co)construção de tecnologias", traz recordações, memórias vivenciadas, a partir das falas dos gestores do Curso Técnico em Apicultura (coordenador de tutores, coordenador de curso e coordenação geral) sobre como ocorreu o curso na modalidade a distância e o processo de interação, colaboração entre os atores sociais envolvidos. Nesse sentido, a questão de pesquisa se origina a partir dessas reflexões: Como se processa o modelo de gestão educacional do Curso Técnico de Educação Profissional de nível médio em Apicultura, na modalidade Educação a Distância, do CTF/UFPI diante das dificuldades apresentadas no início do curso, em 2014?

Nesse estudo, analisou-se o modelo de gestão educacional colaborativo entre a figura do professor-pesquisador e o trabalho dos professores-tutores do Curso Técnico de Educação Profissional de nível médio em Apicultura, na modalidade Educação a Distância, do Colégio Técnico de Floriano (CTF) vinculado a Universidade Federal do Piauí (UFPI) integrante do Programa da Rede e-Tec Brasil. Justifica-se nesse trabalho a importância em compartilhar esse modelo, uma vez que além de ser semipresencial, pôde aplicar novas metodologias, como também possibilitar estratégias diferenciadas presenciais, propiciando outros horizontes, novas perspectivas de formação profissional.

Nesse formato de gestão, buscou-se a parceria da figura do professorpesquisador experiente aliado ao trabalho do professor-tutor presencial e do professor-tutor a distância, devido às dificuldades em encontrar, na região do sudeste do Piauí, profissionais em educação habilitados na área, em ministrar disciplinas específicas relativas ao curso técnico em apicultura. Para isso, foi necessário utilizar essa estratégia de modelo gestacional, solução alternativa, que permitisse apoiar e implementar as diversas atividades técnicas propostas para o curso, a fim de manter a qualidade da educação profissional técnica de nível médio.

Nesse sentido, as construções de formatos pedagógicos no modelo gestacional, adotado não somente para este curso técnico de educação profissional de nível médio, na modalidade de educação a distância na UFPI, mas também para todo o Programa da Rede e-Tec Brasil, pertencente a UFPI, ocorreu na sua abrangência de forma semipresencial. Este direcionamento vai na direção da 
perspectiva apontada por Moran (2003, p. 42) que indica que "[...] estamos caminhando para uma aproximação sem precedentes entre os cursos presenciais (cada vez mais semipresenciais) e os à distância".

Isso ocorre no Curso Técnico de Educação Profissional de nível médio em Apicultura, na modalidade Educação a Distância, do CTF/UFPI, uma vez que na sua maior parte, ocorre via online, ou seja, $75 \%$ por meio das tecnologias digitais, no uso do Ambiente Virtual de Aprendizagem (AVA)-Moodle. O professor-pesquisador, especialista nas disciplinas específicas na área da apicultura, prepara o material teórico e prático a ser adotado na disciplina, sugere material atualizado, materiais complementares, elabora exercícios e temáticas de fóruns e chats de discussão, sendo parceiro do professor-tutor a distância, na condução de suas atividades.

Nesse ambiente virtual acontece o processo interativo entre a figura do professor-pesquisador e o professor-tutor a distância orientando, conduzindo a melhor forma metodológica a ser utilizada para que o referido professor-tutor cumpra com as funções: social, pedagógica, gerencial e suporte técnico (BERGER,1995), no ambiente virtual, e $25 \%$ de forma presencial, nos encontros nos finais de semana (sábados).

Exatamente nesses encontros presenciais - de tira-dúvidas, de explanação de alguma prática metodológica que favoreceu a motivação na participação dos estudantes-produtores rurais em eventos científicos, como também no compartilhamento de experiências, aplicações de saberes teórico-práticos e experienciais nas práticas junto com os apicultores de suas comunidades. Busca-se ensejar oportunidades nas quais "[...] o conhecimento prático deve se articular ao teórico e vice-versa, portanto, refletir sobre a prática envolve a necessidade de rever a teoria e de desvelar as vicissitudes da ação docente" (IBIAPINA, 2008, p. 57).

Essa prestação de serviços, assessoria técnica, interação social com a sua (dos educandos-apicultores) comunidade rural possibilita um aumento na produção de mel na região e a valorização de seus derivados, como também favorece um retorno não somente na economia local, mas também pode levar a que os outros produtores rurais/apicultores sejam multiplicadores desse conhecimento técnico e científico e que incorporado com os seus saberes experienciais possam ser potencializadores para uma transformação individual e coletiva.

Dessa forma, a necessidade de uso de estratégia de modelo gestacional colaborativo permitiu manter a qualidade do ensino técnico e profissional, adotando o apoio da figura do professor-pesquisador aliado ao trabalho do professor tutorpresencial. De acordo com Ibiapina (2008, p. 55), nesse processo colaborativo, reflexivo e dialógico entre os atores sociais,

A linguagem assume um papel extremamente importante, já que é um instrumento indispensável ao aprendizado da colaboração e da reflexividade, uma vez que permite a expressão do pensamento abstrato e dos comportamentos, ajudando a provocar o salto qualitativo do sensorial ao racional, do não conscientizado ao consciente. 
Além disso, no modelo de gestão educacional, no Curso Técnico de Educação Profissional de nível médio em Apicultura, na modalidade Educação a Distância, do CTF/UFPI, possibilitou o inter-relacionamento de estudantes-produtores rurais e professores-tutores em eventos técnicos e científicos nos processos de ensino e aprendizagem, nas aplicações práticas nos campos de suas respectivas comunidades rurais, compartilhando as experiências de outras cidades-polos de apoio presencial, como também possibilitou que nesses encontros científicos fossem despertados nos jovens estudantes-produtores rurais, outros olhares e conhecimentos para a continuação de sua formação na área, em cursos de graduação e pós-graduação.

\section{IMPLANTAÇÃO DO PROGRAMA REDE E-TEC BRASIL: MODELO DE GESTÃO DO CURSO TÉCNICO EM APICULTURA NA EAD NA UFPI}

O Ministério da Educação criou em 2011 o Programa da Rede e-Tec Brasil, Decreto $n^{\circ} 7.589$, o qual faz parte do outro Programa Nacional de Acesso ao Ensino Técnico e Emprego (PRONATEC), com intuito de desenvolver a educação profissional e tecnológica na modalidade da educação a distância, potencializando, ampliando e democratizando a oferta e o acesso à educação profissional pública e gratuita no País (BRASIL, 2011).

Ou seja, o Programa da Rede e-Tec Brasil faz parte da política pública do Governo Federal em atender um público-alvo, na modalidade de educação a distância, visando superar as dificuldades de tal público alvo do acesso a educação. Ao tratar neste artigo da análise do Programa Rede e-Tec Brasil como parte da política pública de educação profissional, devemos ter em conta a importância de conceituação de política pública, considerando que elas se fundamentam essencialmente "nas ações que os governos decidem colocar em prática para solução de problemas públicos" (PEREZ e PASSONE, 2013, p. 621).

Conforme Azevedo (1997, p. 11), o objetivo maior das políticas públicas é de "[...] atender aos setores sociais mais fragilizados e vulneráveis a fim de assegurar direitos". Além disso, o referido autor concebe a definição do conceito de política pública, em dois planos, sendo que:

Em um plano mais concreto implica considerar os recursos de poder que operam na sua definição e que têm nas instituições do Estado, sobretudo na máquina governamental, o seu principal referente. Outra importante dimensão que se deve considerar nas análises é que as políticas públicas são definidas, implementadas, reformuladas ou desativadas com base na memória da sociedade ou do Estado em que têm lugar e que por isso guardam estreita relação com as representações sociais que cada sociedade desenvolve sobre si própria. 
Sendo assim, cabe também considerar que a educação e sua problemática não constituem dimensões fechadas em si-mesmas, mas fazem parte de todo um sistema societário. Por esta perspectiva analítica, as análises dos limites e possibilidades do Programa Rede e-Tec Brasil devem considerar "os modelos educacionais e as políticas educacionais que lhe dão suporte [pois] somente se tornam plenamente compreensíveis se referidos ao modelo societário do qual fazem parte e no qual se encontram sua explicação, justificação e também os seus elementos contraditórios". (LIMA FILHO, 2015, p. 199).

No Piauí, o Programa Rede e-Tec Brasil fora implantado pelo Instituto Federal de Educação Ciência e Tecnologia do Piauí (IFPI) e pela UFPI. Devido essa instituição de ensino educacional ter experiências nos cursos de graduação e pósgraduação por meio da modalidade a distância, pela Universidade Aberta do Brasil (UAB), ampliou também a ofertas de cursos da Educação Profissional e Tecnológica.

No caso específico da oferta do Curso Técnico de Educação Profissional de nível médio em Apicultura, do CTF/UFPI, esta se deve ao fato de que o estado do Piauí se destaca na produção de mel. Isso se reflete na economia local e regional e fez com que repercutisse o interesse em implantar uma política pública educacional na região, a fim de contribuir para aperfeiçoar as técnicas, procedimentos e manejos adequados na área da apicultura. Um mercado competitivo e exigente, com produtos cada vez mais de excelência na qualidade, implicou a necessidade da criação do Curso Técnico em Apicultura no Estado do Piauí, para que contribua nos processos de produção com uma formação técnica e científica. Essa criação se deveu à solicitação de acordo com a demanda do produtor rural, juntamente com o apoio da representação da Federação de Entidades Apícolas do Piauí (FEAPI). (UNIVERSIDADE FEDERAL DO PIAUÍ, 2014a).

O modelo de gestão educacional do Curso Técnico em Apicultura funciona de forma intensa, interativa, participativa de forma atuante, exigindo o diálogo e a reciprocidade mútua entre os gestores e docentes, cada qual cumprindo com seu papel, mas interagindo, inter-relacionando entre si para alcançar objetivos em comum, caracterizando um processo colaborativo e democrático, uma vez que a:

Participação se funda no exercício do diálogo entre as partes. Esta comunicação ocorre, em geral, entre pessoas com diferentes formações e habilidades, ou seja, entre agentes dotados de distintas competências para a construção de um plano coletivo e consensual de ação (CATANI; GUTIERREZ, 2003, p. 71).

Para compreensão desse modelo, inicialmente o projeto piloto do curso, foi implantado nas regiões piauienses, com o suporte dos Polos de Apoio Presenciais de: Simplício Mendes, Picos e São Raimundo Nonato, em 2014. (UNIVERSIDADE FEDERAL DO PIAUÍ, 2014b). Ressalta-se a dificuldade da presença diária na cidadepolo educacional dos estudantes, uma vez que estes atuam também como produtores rurais ajudando os familiares em outras atividades no campo, além das atividades como apicultores, vivem em comunidades distantes e de difícil acesso. 
Por esse motivo, o Programa Rede e-Tec Brasil, buscando atender o anseio desses trabalhadores, trouxe às comunidades rurais a possibilidade de realizar um Curso Técnico, obter uma formação técnica sem ter que sair do seu local de moradia. Com a parceria entre a SETEC/MEC - CTF/UFPI e Prefeituras Municipais, houve a chance de fazer com que isso se tornasse realidade, levando esse curso com profissionais qualificados para os interiores.

A primeira instituição de ensino brasileira a ofertar o Curso Técnico em Apicultura, na modalidade presencial, foi a Universidade Federal do Piauí, em 2013, via PRONATEC. Não obstante, também foi quem primeiro realizou o mesmo curso na modalidade a distância, via Rede e-Tec Brasil, em 2014. (UNIVERSIDADE FEDERAL DO PIAUÍ, 2014b).

Nesse sentido, o Programa Rede e-Tec Brasil, possibilita facilitar a gestão do tempo e veio para contornar a situação de enfrentar custo de deslocamento a distância, na sua própria região, por meio das tecnologias da informação e comunicação (TIC).

Os novos esquemas cognitivos, com o desenvolvimento da cibercultura, entre outros fatores, vêm possibilitar, na área da educação, novas compreensões sobre o processo de ensinar e de aprender, calcadas em recursos que conectam e criam relações entre sujeitos, pelas diversas redes de informação que vão sendo constituídas - do mundo científico, artístico e cultural. (MACIEL, 2010, p. 4).

Ressalta-se que o Curso Técnico em Apicultura nessa modalidade funciona de forma semipresencial, pois na sua maior parte, funciona por meio do ambiente virtual de aprendizagem (AVA)-Moodle, com o auxílio, suporte orientação do professor-tutor a distância, mediando fóruns e chats de discussão, como também tirando dúvidas por celulares, WhatsApp, facebook, dentre outras tecnologias. Os $25 \%$ dos encontros presenciais são executados aos sábados, no polo de apoio presencial sanando/minimizando dúvidas ou são realizadas metodologias diferenciadas, realizando visitas técnicas, seminários, convidando especialistas de outros Órgãos/Instituições para compartilharem suas experiências e conhecimentos técnicos e científicos, ou mesmo aplicando a teoria no próprio apiário das comunidades rurais, uma vez que a maior parte desses estudantes-produtores rurais trabalhadores são experientes na área apícola e conhecem o contexto da realidade local.

No ambiente virtual, por meio do AVA-Moodle buscou-se a (co)construção de conhecimentos, compartilhamento de saberes experienciais, por meio das tecnologias digitais, representando os processos de ensino e de aprendizagem no "estar junto virtual". Esse processo, "[...] prevê um alto grau de interação entre professor e alunos, que estão em espaços diferentes, porém interagindo com a internet". (VALENTE; MORAN, 2011, p. 25). Nesse cenário virtual é possível haver as inter-relações, feedback entre os estudantes-estudantes e estudantes e professores; mas também é 
possível perceber o processo dialógico, a atuação/participação mútua entre os participantes.

\begin{abstract}
Essa interação também desenvolve o senso crítico e a capacidade de trabalhar em equipe, ajudando a criar a sensação de pertencimento a uma comunidade. Um recurso dos ambientes virtuais de aprendizagem (AVAS) interessante nesse sentido é a possibilidade de os próprios alunos avaliarem as atividades e contribuições dos colegas. (MATTAR, 2012, p. 41).
\end{abstract}

É um local de convivência, é um espaço para "[...] estar-se e colocar-se ativamente, propiciando a colaboração e participação individual e grupal, e é onde ocorre essa interação cotidiana oportunizada através da escrita, o social, cultural, histórico, político e econômico dos participantes, principalmente, o falar e o ouvir". (AUTOR 1, 2014, p. 42). Também é um local para ser retornado e nesse ambiente é possível orientar, aconselhar, tirar dúvidas/minimizar dificuldades, mediar, estimular/motivar a interação entre os atores sociais envolvidos, a fim de que facilite os processos de ensino e de aprendizagem propiciando a construção de conhecimentos e de tecnologias, como o aperfeiçoamento de manejos, de técnicas, de procedimentos e de métodos adequados.

No ambiente virtual ocorre a interação, o feedback entre os atores sociais uma vez que envolve a participação ativa entre eles, num processo de diálogo interativo, de forma contínua, propiciando o aprendizado mútuo, o compartilhamento de saberes experienciais, possibilitando um espaço de convivência, em que "[...] a busca de "territórios" negociáveis parece ser fundamental para que possamos efetivar o encontro, as convivências, as trocas, por fim, a elaboração" (ALONSO, 2005, p. 32), oportunizando novas (co)construções de conhecimentos e de tecnologias. Além disso, ressalta-se que esse processo de ensino e aprendizagem, na sala de aula (virtual),

Não mais centrada na figura do professor, possuidora permanente de diversos centros onde se dão a constante construção e renegociação dos atores em jogo. Nela, a aprendizagem se dá com as conexões de imagens, sons, textos, palavras, diversas sensações, lógicas, afetividades e com todos os tipos de associações. (SILVA, 2003, p. $56)$.

O "estar junto virtual" visa constituir um cenário propício para compartilhar os saberes técnicos e científicos, como também aprender outros conhecimentos como os saberes experienciais, valorizando conhecimentos prévios dos estudantesprodutores rurais, com intuito de qualificá-los, com uma formação técnica, capaz de abrir novos horizontes, tornando-os cidadãos críticos, reflexivos para o mundo.

Ademais, a concepção de "estar junto virtual" nos remete à necessária compreensão crítica que não se trata de substituição da relação presencial por 
ambientes virtuais apoiados somente em novas tecnologias de informação. É fundamental refutar concepções dicotômicas oriundas de um certo "fetichismo tecnológico" da inevitabilidade e perfeição do progresso tecnológico e organizacional (HARVEY, 2018). Ao contrário, consideramos que em ambas perspectivas (presencial e não-presencial) são fundamentais as interações e mediações produzidas nas relações diretas entre educandos e educadores. Nesse sentido, a investigação acerca do modelo colaborativo-participativo de gestão da educação profissional, objeto deste artigo, deve considerar que trata-se de:

conhecer e discutir quais as possibilidades e práticas facilitadoras que podem ensejar e, por outro lado, conhecer os limites e obstáculos, para que o aporte das novas tecnologias de informação e comunicação se realize como contribuição para a construção de um processo de formação humana integral, científico-tecnológico, ético-político e crítico-reflexivo (AUTOR 2, 2013, p. 6).

\section{TRILHA METODOLÓGICA}

No corpus teórico-metodológico da pesquisa trata-se da pesquisa narrativa, de abordagem qualitativa. Utilizou-se a questão gerativa narrativa apoiado por Flick (2009) e Jovchelovich e Bauer (2010), além da análise bibliográfica e entrevistas narrativas. O cenário de pesquisa foi o Polo de Apoio presencial de São Raimundo Nonato/PI, vinculado ao CTF/UFPI.

Esse estudo se embasou nas características inerentes da pesquisa narrativa, recordando fatos, momentos, como opção metodológica investigativa correlacionada com "[...] os fenômenos, as atividades, o ambiente e os problemas" (STAKE, 2011, p. 189) rememorados nas narrativas dos atores sociais da pesquisa. "Narrar não é simplesmente contar uma história, é se reportar a momentos singulares que jamais se apagarão da memória com o objetivo de trazer à tona momentos de reflexões sobre sua prática pedagógica". (AUTOR 1, 2012, p. 29).

Os colaboradores selecionados da pesquisa foram cinco profissionais: os docentes e gestores que fizeram parte Curso Técnico em Apicultura do CTF/UFPI, vinculado ao Programa Rede e-Tec Brasil, no período de 2014-2016, do Polo de Apoio presencial de São Raimundo Nonato/PI, por ser a maior região do sudeste piauiense e que aceitaram participar voluntariamente da pesquisa.

Utilizou-se a técnica de análise de conteúdo, fundamentada por Bardin (2016) para analisar os dados produzidos na pesquisa, os quais foram organizados no eixo temático: "GESTÃO COLABORATIVA DO CURSO TÉCNICO EM APICULTURA NA EAD DA UFPI".

Por meio da análise e interpretação das narrativas de cinco colaboradores da pesquisa, sendo três gestores e dois docentes, delineamos as discussões de como se processou o modelo de gestão educacional do Curso Técnico em Apicultura, na EaD, do CTF/UFPI, diante das dificuldades na implantação do curso em 2014. 


\section{RESULTADOS E DISCUSSOES}

Os colaboradores da pesquisa ao contar sobre suas experiências e vivências cristalizam, por meio da linguagem dialógica, fatos, recordações que dão indícios sobre o modelo de gestão educacional do curso Técnico em Apicultura na EaD, do CTF/UFPI, ocorrido no período de 2014-2016.

[...] Foi um desafio para todos nós, pois construímos o projeto pedagógico [...]. Nesse formato semipresencial, [...] você tem [...] um tutor que [...] que conhece boa parte dos problemas da região e isso facilitou muito [...] a nossa compreensão, com relação à implementação efetiva dentro da plataforma pelos problemas de internet, que nós temos dentro dos polos, [...] mas isso foi superado [...] por parte do grupo, [outros gestores do curso]. Usamos a plataforma moodle, de forma dinâmica, o sistema semipresencial, um contato muito intenso, com o tutor e com os estudantes de forma que a gente pudesse superar essa barreira. [...] Que eles estavam no polo dele, mas que o projeto era em três polos, que eles entendessem que era um projeto piloto, que a gente precisava superar juntos, todas as dificuldades [...] A gente faz a ponderação que o sistema a distância, de forma semipresencial funciona muito bem, até porque a gente tem a aproximação física, com o professor-tutor lá na região e isso aproxima e muito, principalmente a relação entre a teoria e a prática. Nós temos a dimensão motriz-operacional bem executada, [...] dimensionada. [...] A gente inclusive recomenda que a gente possa replicar no futuro bem próximo essa experiência em outros polos apícolas, do qual a gente já tem ideia de quais pontos que a gente teria que atacar. (Entrevista Colaborador1, 2019).

Apesar dos gestores terem enfrentado inúmeras dificuldades durante a implantação do Curso Técnico em Apicultura, na EaD, como o problema de conexão de Internet, o Colaborador1 ressalta a importância da parceria/interação, pois "[...] nos trabalhos colaborativos, os partícipes se colocam como aprendizes, apreendendo com as experiências, os conhecimentos, as reflexões, objetivos e organização cognitiva e afetiva do outro". (IBIAPINA, 2016, 47). Nesse caso, a colaboração das outras coordenações, enfrentando juntos os problemas em comuns, como ponto fundamental (coordenação de curso, coordenação geral, juntamente com o trabalho da coordenação de polo de apoio presencial), a fim de saná-los/minimizá-los para a continuidade da realização do curso.

Além disso, nas entrelinhas de sua narrativa aborda a preocupação do gestor de que o estudante saiba sobre a funcionalidade do modelo de gestão semipresencial do curso técnico em apicultura, para que o mesmo compreenda na sua totalidade o funcionamento do projeto piloto pioneiro no Brasil nessa modalidade à distância e ressalta-se a importância da oferta da política pública educacional na modalidade a distância, como possibilidade de mantê-la e ampliá-la, em outras regiões apícolas no processo de coconstrução de tecnologias sociais. 
No início do curso, a gente encontrava muitas dificuldades, especialmente em achar professores capacitados, especialistas e experientes na redondeza da região. Então a gente teve a ideia de aliar um profissional experiente, que é a figura do professorpesquisador, [...] que pudesse nos ajudar nesse sentido, dando um suporte para o tutor a distância, que tinha poucas habilidades com as tecnologias digitais no ambiente virtual, e para o tutor presencial que tinha muita bagagem teórica, mas pouca prática, buscando formas metodológicas diferentes, incentivando aos alunos a participar de eventos científicos, de interagirem com as comunidades rurais, de compartilharem experiências apícolas, de aplicarem na prática os conhecimentos teóricos e científicos, apreendidos em sala, dentre outros, já que o modelo não é totalmente a distância, mas semipresencial. (ENTREVISTA COLABORADOR2, 2019).

Nota-se nas narrativas do Colaborador2 e Colaborador5 a estratégia de gestão educacional colaborativa, solução alternativa de compartilhar as práticas docentes do pesquisador colaborador experiente, com os saberes experienciais do professor-tutor de carreira inicial. A pesquisadora lbiapina (2016, p. 44) informa que "[...] é no movimento reflexivo-colaborativo que a atividade docente vem à tona com o potencial de análise, interpretação e transformação das realidades educativas". Nesse sentido, no processo dinâmico, reflexivo e interativo, pode envolver a mudança do percurso, quando os objetivos em comum do grupo forem alterados ou influenciados por interesses pessoais individualizados.

Além disso, também abrange o ato de criar e o de produzir, reunindo diferentes técnicas, procedimentos e tecnologias na preparação de cada etapa planejada que será executada no tempo pré-determinado e no local adequado, com movimentos regulares e/ou irregulares, passando de um nível para o outro, como se fosse um espiral, análogo a um jogo, até alcançar o resultado desejado.

As estratégias foram além da teoria. Além das aulas presenciais nos finais de semanas, houveram práticas no Centro de Tecnologia Apícola que consistiram no estágio dos alunos. Então, durante o estágio eles participaram do manejo do apiário experimental, de visitas as Associações para a realização do perfil dos Apicultores da microrregião de Picos, auxiliaram em análises laboratoriais (análises de determinadas patologias apícolas), além de visitas técnicas, como a visita a Casa de Pólen em Esperantina. Os alunos foram incentivados a executar pesquisas e apresentaram seus trabalhos no Congresso Brasileiro de Apicultura em 2016. Essas práticas foram muito positivas para a construção do conhecimento em diversas áreas da Apicultura e proporcionaram aos alunos uma visão mais ampla da atividade em sua região. Além disso, podemos destacar uma aluna [...] que seguiu em sua graduação em Agronomia, tendo seu trabalho de conclusão de curso desenvolvido na área. Atualmente desenvolve o 
mestrado em extensão rural tendo como tema também a Apicultura. (ENTREVISTA COLABORADOR3, 2019).

O Colaborador3 ressalta sobre a importância da experiência e vivência dos estudantes-produtores rurais participarem em eventos científicos, na interação entre eles nos experimentos de laboratórios de análises, em visitas técnicas, nas visitas nos apiários com a colaboração da comunidade, aplicando na prática, os conhecimentos teóricos apreendidos em sala de aula.

A colaboração, portanto, que ocorre em contexto de pesquisa acadêmica, é produzida por intermédio de interações questionadoras sobre as práticas educativas que os docentes desenvolvem, tendo o pesquisador o potencial de escolher, em comum acordo com os docentes, os procedimentos de confronto e de reelaboração destas práticas no decorrer da organização formal da investigação. (IBIAPINA, 2016, p. 44).

Essas experiências, essas interações são outras formas de aquisição de conhecimentos teóricos-científicos aliados aos saberes experienciais de seus parceiros colegas apicultores, formas metodológicas distintas e dinâmicas, como formas de despertar outros olhares na obtenção de novos conhecimentos científicos, na continuação de sua formação na área, em cursos de graduação e pós-graduação.

A experiência provoca um efeito de retomada crítica (retroalimentação) dos saberes adquiridos antes ou fora da prática profissional. Ela filtra e seleciona os outros saberes, permitindo assim aos professores reverem seus saberes, julgá-los e avaliá-los e, portanto, objetivar um saber formado de todos os saberes retraduzidos e submetidos ao processo de validação constituído pela prática cotidiana. (TARDIF, 2002, p. 53).

Todos os colaboradores enfocam a importância do modelo de gestão do curso de não ser $100 \%$ à distância, pois o formato semipresencial permite a aproximação física do professor-tutor presencial na e da região, conhecendo o contexto da realidade dos estudantes-produtores rurais, com seus hábitos, com seus valores, seu modo de vida, suas peculiaridades; e essa aproximação facilita a aplicação teóricoprático no contexto local, contribuindo para os processos de ensino e de aprendizagem. "[...] Na reflexividade, o professor mergulha na prática e traz à tona a teoria para compreender de forma mais clara os conceitos que guiam a atividade docente. (IBIAPINA, 2008, p. 47). 
A existência do tutor presencial para conduzir os encontros [...] Com material previamente preparado pela coordenação e afinado com as orientações estabelecidas no programa pedagógico permitiu que os conteúdos pudessem ser cumpridos a cada encontro. Como os cursos aconteceram nas áreas onde a atividade era forte, muito alunos tiveram a oportunidade de através das visitas de campo vivenciar 0 conteúdo teórico apresentado. A grande dificuldade encontrada foi o fato deste ter sido o primeiro curso dessa natureza em apicultura e tudo era muito novo. Os materiais foram sendo construídos à medida que o curso prosseguia... sendo ajustado as necessidades das turmas. Considero exitosa a realização do curso, principalmente por ter oportunizado o aprimoramento técnico de filhos de apicultores em regiões onde a apicultura é uma atividade social e econômica importante. [Além disso,] considerando que tínhamos contato direto com os tutores e tratava-se de pessoas com conhecimento da área na região, a interação para se contornar as dificuldades nos polos foram facilitadas. Um ponto favorável também foi o interesse dos alunos pelo curso. (ENTREVISTA COLABORADOR4, 2019).

$\mathrm{Na}$ concepção do Colaborador4 o modelo de gestão funcionava de forma intensa, uma vez que se tratava de profissionais da área, de conhecedores das dificuldades e peculiaridades da região em que se encontravam. Desse modo, os profissionais da educação colaboravam para que a interação entre as partes fizesse com que a integração do sistema acontecesse. De acordo com Freire (2004), o mesmo informa sobre como informar, descrever a ação, como confrontar e (re)construir na perspectiva da reflexão como se poderia agir forma distinta.

Além disso, nas inferências de suas narrativas, o mesmo assegura momentos de reflexão, no sentido de que como o curso nessa modalidade a distância, era novo, pioneiro a nível nacional e havia as peculiaridades do perfil de estudantes-produtores rurais de outras regiões, houve a necessidade de adaptação dos materiais didáticos. Ibiapina (2008, p. 46) assevera que o "[...] trabalho colaborativo e reflexivo é organizado por meio de ações formativas que auxiliam no processo de co-produção de conhecimentos". Isso é um movimento de autorreflexão sobre suas e nas ações, a fim de poder contribuir no e sobre o próximo curso que poderão surgir, na EaD, nas cidades-polos apícolas, que são tão carentes de formação técnica.

A metodologia do curso [...] Técnico em Apicultura []do Programa Rede e-Tec Brasil foram aplicadas aulas teóricas e práticas, pois sendo um curso técnico, só nos sábados[semipresencial], busquei a ideia juntamente com o [coordenador geral e coordenador de polo] de se trabalhar com aulas práticas com especialistas nos assuntos. A maioria dos alunos vinha de experiência em escolas técnicas e alguns já eram apicultores do território, com larga experiência, com isso ficou mais fácil o trabalho na sala, pois havia o comprometimento dos alunos e a busca de informações a respeito do curso. Tivemos a experiência de trazer pessoas do próprio território de outras instituições para proferir palestras, cursos do SEBRAE, SENAR, além 
de visitas técnicas, participação em seminários, contribuindo para um trabalho focado em técnicas inovadoras e no empreendedorismo, buscando sempre a sustentabilidade ambiental. (ENTREVISTA COLABORADOR5, 2019).

O colaboradora5 ressalta a facilidade que teve em adotar técnicas diferenciadas, metodologias mais dinamizadas em inserir em sala de aula, nos momentos presenciais, interagindo e envolvendo com a sociedade e a turma, buscando profissionais especialistas na área que pudessem colaborar e aprimorar os conhecimentos técnicos e científicos de forma mútua, uma vez que boa parte dos estudantes-produtores rurais já vinha com uma outra formação profissional para o curso técnico em apicultura, facilitando os processos de ensino e de aprendizado.

As ações do Colaborador5 como docente refletem, por outro lado, o compromisso dos estudantes para com o curso técnico, para com o professorpresencial, na "[...] igualdade de oportunidades dos participantes da interação em colocar em discussão sentidos/significados, valor e conceitos que vêm embasando suas ações, escolhas, dúvidas e discordâncias" (CELANI, 2003, p. 27), caracterizando tais práticas docentes como autorreflexão para trilhar passos como uma condicional para pensar e agir sobre o ser e o fazer do profissional, de forma crítica e criativa.

O referido Colaboradora5 menciona também em sua narrativa sobre a preocupação na sustentabilidade ambiental em suas práticas. Nesse sentido, constata-se que nesses encontros presenciais buscou-se "[...]contribuir para a formação de cidadãos atuantes e participativos, bem como, docentes comprometidos com sua colaboração formativa e informativa do cotidiano escolar, embasados nos preceitos da ética e da responsabilidade social". (AUTOR 1, 2014, p. 42). Muitas aplicações dos conhecimentos teóricos executados na prática, no campo/no apiário, como a criação de ferramentas para a utilização e realização de técnicas de manejos adequados na colmeia, reaproveitamento de garrafas pets para o reuso de bebedouro artificial, são exemplos de cuidado do meio ambiente.

\section{CONSIDERAÇÕES FINAIS}

Nota-se nesse estudo, a importância do trabalho entre os profissionais em educação, apoiando uns aos outros e enfrentando as dificuldades de forma coletiva, interativa, especialmente colaborativa, no modelo de gestão do Curso Técnico de Educação Profissional de nível médio em Apicultura, na modalidade Educação a Distância, da Universidade Federal do Piauí (UFPI). Para além da aplicação no próprio curso pesquisado, vislumbrou-se possibilidades de que o conhecimento teóricoprático produzido nesta experiência de gestão colaborativa seja levado como contribuição a outros cursos inerentes ao Programa da Rede e-Tec Brasil.

No caso estudado, ressalta-se a estratégia de gestão educacional em utilizar a figura do professor-pesquisador como peça fundamental para alavancar, mobilizar ações impulsionadoras, dinâmicas, motivadoras tanto para os docentes quanto para os estudantes-produtores rurais que tiveram a oportunidade de serem inseridos em 
pesquisas científicas, laboratórios, eventos científicos, contato direto com visitas técnicas, envolvimento práticos com outras comunidades apícolas, proporcionandoIhes a (co)construção do conhecimentos nas diversas áreas da apicultura, enriquecido juntamente com seus saberes experienciais, propiciando-Ihes uma visão mais ampla das atividades em que atuam em sua região, com vistas à melhoria da qualidade, da produtividade e ao fortalecimento dos processos de empoderamento social e coletivo.

Consta-se nas narrativas dos colaboradores, fatos essenciais que vieram à tona como forma de rememorizar suas práticas docentes, suas ações como gestores, cristalizadas na linguagem, que dão pistas na importância da oferta da política pública educacional na modalidade a distância, como possibilidade de mantê-la e ampliá-la, no processo de coconstrução de tecnologia social, carente de formação técnica e científica, de forma a que venha a contribuir para o aumento da produção na apicultura, uma vez que a mesma é uma alternativa ou principal fonte de renda para o sustento familiar dos trabalhadores rurais dos contextos analisados nesta pesquisa.

\section{REFERÊNCIAS}

ALONSO, K. M. Algumas considerações sobre a educação a distância, aprendizagens e a gestão de sistemas não-presenciais de ensino. In: PRETI, et al. Educação a distância: ressignificando práticas. Brasília, DF: Liber Livro, 2005. p. 17-38.

AZEVEDO, Márcio Adriano de. Pesquisa em avaliação de políticas públicas e o Programa Escola Ativa: 20 anos depois. Curitiba: CRV, 2018.

BARDIN, L. Análise de Conteúdo. Lisboa, PT: Edições 70, 2016.

BERGER, Z. L. Estudos de caso de exemplo em ensino poste secundário, online. In: HART, G.; MASON, J. Procedimentos de 'O Simpósio Universitário Virtual. Melbourne, Austrália, 21-22 de novembro de 1996. p. 99-105.

BRASIL. Ministério da Educação. Rede e-Tec Brasil: Apresentação. Brasília, DF, 2011. Disponível em: < http://portal.mec.gov.br/rede-e-tec-brasil>. Acesso em: 04 maio 2020.

BRASIL. Ministério da Educação. Pronatec: O Pronatec. Brasília, DF, 2013. Disponível em: <http://portal.mec.gov.br/pronatec/o-que-e>. Acesso em: 08 abr. 2019.

CATANI, A. M.; GUTIERREZ, G. L. Participação e gestão escolar: conceitos e potencialidades. In. FERREIRA, Naura Syria Carapeto (Org). Gestão democrática da educação: atuais tendências, novos desafios.4. ed. São Paulo, SP: Cortez, 2003.

CELANI, M. A. A. Um programa de formação contínua. In: Professores e formadores em mudança: relato de um processo de reflexão e transformação da prática docente. Campinas, São Paulo: Mercado de Letras, 2003.

FREIRE, P. Pedagogia da autonomia: saberes necessários à prática educativa. 29. ed. Rio de Janeiro: Paz e Terra, 2004. 
FLICK, U. Narrativas. In:

(Org.). Métodos de Pesquisa: Introdução à

Pesquisa Qualitativa. Tradução de Joice Elias Costa. 3. ed. Porto Alegre, RS: Artmed, 2009. p. 164-178.

HARVEY, D. A loucura da razão econômica: Marx e o capital no século XXI. São Paulo: Boitempo, 2018.

IBIAPINA, I. M. L. de M. Pesquisa colaborativa: investigação, formação e produção de conhecimentos. Brasília, DF: Líber Livro, 2008.

IBIAPINA, I. M. L. de M. REFLEXÕES SOBRE A PRODUÇÃO DO CAMPO TEÓRICO-METODOLÓGICO DAS PESQUISAS COLABORATIVAS: gênese e expansão. In: IBIAPINA, I. M. L. de M.; BANDEIRA, H. M.; ARAUJO, F. A. M. (org.). Pesquisa colaborativa: multirreferenciais e práticas convergentes. Teresina, $\mathrm{PI}$ : EDUFPI, 2016. p. 33-62.

JOVCHELOVITCH, S.; BAUER, M. W. Entrevista Narrativa. In: BAUER, M. W.; GASKELL, G. (Org.). Pesquisa qualitativa com texto, imagem e som: um manual prático. Petrópolis, RJ: Vozes, 2010. p. 90-113.

"Autor 2". Capítulo de livro. In: Organizadores do livro. Título do livro. Cidade: editora, 2013.

"Autor 1"; "Autor 2". Capítulo de livro. In: Organizadores do livro. Título do livro. Cidade: editora, 2017. p. 319-337.

"Autor 1". Título. Dissertação (Mestrado) - Universidade, Centro, Cidade, 2012. $198 p$.

"Autor 1". Capítulo de livro. In: Organizadores do livro. Título do livro. Cidade: editora, 2014, p. 133-144.

LIMA FILHO, D. L. Expansão da educação superior e da educação profissional no Brasil: tensões e perspectivas. Revista Educação em Questão, Natal, v. 51, n. 37, p. 195-223, jan./abr. 2015

MACIEL, I. M. Educação a Distância - Ambiente Virtual: Construindo Significados. 2010. Disponível em: <

https://www.aedi.ufpa.br/parfor/letras/images/pdf/at_distancia/castanhal_1.2013/cast anhal_2010.020/1.2013\%20castanhal\%202010-

020\%20tecn.\%20ed.\%20e\%20ens.\%20do\%20port.\%20texto\%20iii\%20profa.\%20will iane\%20santos.pdf >. Acesso em: 21 mar. 2019.

MATTAR, J. Tutoria e interação em educação a distância. São Paulo: Cengage Learning, 2012.

MORAN, J. M. Perspectivas (virtuais) para a educação. Cadernos Adenauer, IV, 2003, n. 6, Rio de Janeiro, Fundação Konrad Adenauer, abril 2004. (Mundo Virtual).

PEREZ, José Roberto Rus. PASSONE, Eric Ferdinando Kanai. Psicologia e análise de implementação de políticas públicas: um diálogo interdisciplinar. Psicologia: ciência e profissão, Brasília, 33(3), 2013, p. 612-629.

SILVA, M. Criar e professorar um curso online: relato de experiência. In: SILVA, M. (org.). Educação Online. 3. ed. São Paulo: Edições Loyola, 2003. p. 53-75. 
STAKE, R. E. Pesquisa qualitativa: estudando como as coisas funcionam. Tradução de Karla Reis. Porto Alegre, RS: Penso, 2011.

TARDIF, M. Saberes docentes e formação profissional. Petrópolis, RJ: Vozes, 2002.

VALENTE, J. A.; MORAN, J. M. Pontuando e contrapondo. In: ARANTES, V. A. (org.). Educação a distância: pontos e contrapontos. São Paulo: Summus, 2011. p. 87-108.

UNIVERSIDADE FEDERAL DO PIAUÍ. Colégio Técnico de Floriano. Ata da Reunião Extraordinária do Ensino Técnico a Distância - Rede e-Tec Brasil, do Colégio Técnico de Floriano, maio 2014. Floriano, PI: CTF, 2014a.

UNIVERSIDADE FEDERAL DO PIAUÍ. Colégio Técnico de Floriano. Projeto Político Pedagógico do Curso Técnico em Apicultura na modalidade à distância da Rede e-Tec Brasil. Floriano, PI: CTF, 2014b. 